\title{
Metas de socialização e estratégias de ação paternas e maternas ${ }^{1}$
}

\author{
Pollyane Kahelen da Costa Diniz ${ }^{2}$ \\ Victoria University of Wellington, Nova Zelândia \\ Nádia Maria Ribeiro Salomão \\ Universidade Federal da Paraíba, João Pessoa-PB, Brasil
}

\begin{abstract}
Resumo: O presente estudo objetivou investigar as metas de socialização de mães e pais acerca do futuro dos seus filhos. Adicionalmente, pretendeu-se verificar a influência do gênero da criança nas metas traçadas pelas mães e pais e averiguar a concepção destes acerca do papel que devem desempenhar para que as metas se realizem. Participaram 26 casais residentes na cidade de João Pessoa, Paraíba. Os participantes responderam a uma entrevista semi-estruturada. As entrevistas foram gravadas, transcritas e, posteriormente, analisadas em categorias. Verificou-se que as metas de socialização referentes à categoria auto-aperfeiçoamento e expectativas sociais prevaleceram nos relatos dos participantes, sendo que os pais apresentaram mais expectativas sociais para os meninos. No que se refere às estratégias de ação, observou-se maior menção, por parte dos participantes, a estratégias centradas em si. As implicações destes resultados para o conhecimento na área do desenvolvimento infantil e familiar são discutidas e futuras pesquisas sugeridas.
\end{abstract}

Palavras-chave: desenvolvimento infantil, socialização, pais, gênero.

\section{Parents socialization goals and action strategies}

\begin{abstract}
This study aimed to investigate mothers and fathers socialization goals about the future of their children. Additionally, it aimed to evaluate a child's gender influence in the goals outlined by the parents and, also, investigate their conceptions about the role they must play for these goals to be accomplished. In this study, 26 couples participated, all residents in João Pessoa city, Paraíba, Brazil. They answered a semi-structured interview about socialization goals. The interviews were recorded, transcribed, and later analyzed according to the categories. It was verified that the socialization goals for self-improvement and social expectation categories prevailed in the accounts of the participants, although fathers had more social expectation towards boys. Regarding action strategies, there was a higher number of verbalizations related to self centered strategies. The implications of these findings to child development and family studies are discussed and future research is suggested.
\end{abstract}

Keywords: child development, socialization, parents, gender.

\section{Objetivos de socialización y estrategias para la acción materna y paterna}

Resumen: El presente estudio investigó las metas de socialización y estrategias de acción de padres y madres sobre el futuro de sus hijos. Además, se pretendió verificar la influencia del sexo del niño en las metas establecidas por las madres y los padres y la concepción de estos sobre el papel que deben desempeñar para que estas metas se realicen. Participaron 26 parejas residentes en la ciudad de João Pessoa, Paraíba, Brasil. Éstos respondieron a una entrevista semi-estructurada. Las entrevistas fueron grabadas, transcritas y analizadas de acuerdo a categorías. Se constató que las categorías auto-perfeccionamiento y expectativa social prevalecieron en los relatos, y que los padres tenían más expectativa social para con los niños. También se observó una mayor mención a las estrategias centradas en si mismo. Las implicaciones de estos resultados a los conocimientos en el ámbito del desarrollo del niño y la familia son discutidas e investigaciones futuras son propuestas.

Palabras clave: desarrollo infantil, socialización, padres, género.

O processo de socialização da criança pressupõe a aquisição de valores, normas, costumes, papéis, conhecimentos e condutas que são transmitidos e regulados pela sociedade. Nesse contexto, a família constitui o nicho de desenvolvimento primário (Keller, 1998) oportunizando situações interativas entre seus membros. Assim, as características de personalidade

\footnotetext{
1 Este trabalho é derivado de Monografia de conclusão de curso da primeira autora, sob orientação da segunda, no curso de graduação em Psicologia da Universidade Federal da Paraíba. Este texto foi revisado segundo o Acordo Ortográfico da Língua Portuguesa (1990), em vigor a partir de $1^{\circ}$ de janeiro de 2009.

2 Endereço para correspondência:

Pollyane Kahelen da Costa Diniz. Victoria University of Wellington. Centre for Applied Cross-Cultural Research. School of Psychology. PO Box 600.Wellington, New Zealand 6140.

E-mail: Pollyane.Diniz@vuw.ac.nz
}

e as cognições e crenças dos pais sobre as motivações e capacidades da criança são significativas na modelação de práticas disciplinares (Bridges, Connell, \& Belsky, 1988).

A literatura especializada na área de estudo dos sistemas de crenças parentais tem denominado de metas de socialização os ideais implícitos ou explícitos dos pais com relação à maneira que gostariam que seus filhos fossem, ou seja, que conhecimentos, valores morais e padrões de comportamento estes pais acreditam que seus filhos deveriam adquirir à medida que crescessem (Miller \& Harwood, 2001). Desse modo, as metas de socialização orientariam o uso de estratégias educativas por parte dos pais na tentativa de atingir tais ideais. Ao utilizarem tais estratégias, os pais tentam estabelecer um compromisso com seus valores pessoais e, ao mesmo tempo, com os valores sociais que regulamentam o comportamento aceitável (Leyendecker, Lamb, Harwood, \& 
Schölmerich, 2002). Antes de tratar especificamente a temática das metas de socialização, parece pertinente, no entanto, abordar como este processo é empreendido pela família e que papéis são desempenhados pelos pais e mães neste contexto.

\section{O processo de socialização no contexto familiar}

Tendo em vista a importância da família no processo de socialização especialmente durante a primeira infância, têm sido empreendidos esforços para defini-la. De maneira consensual, a família é entendida como espaço composto por pessoas de idades diversificadas e que estão, desta forma, em momentos de desenvolvimento diferentes, avançando juntas em um ciclo vital marcado por eventos críticos, definidores de etapas evolutivas e de tarefas de socialização (BiasoliAlves, 1997). Além disso, a família deve ser compreendida dentro da cultura em que está inserida, com sistemas simbólicos e padrões comportamentais diversos. Desse modo, as experiências concretas interacionais variam segundo os cenários (Keller, 1998) e tal diversidade tem implicações importantes sobre como os pais pensam o processo de criação dos filhos.

Além desses aspectos, a literatura aponta que pais e mães desempenham papéis diferenciados dentro da família, proporcionando, cada qual, já na primeira infância, experiências interacionais qualitativamente diferentes a seus filhos (Bridges e cols., 1988; Dessen, 1997; Ely \& Gleason, 1997; Zamberlan \& Biasoli-Alves, 1997). Segundo uma visão tradicional (Field, 1978), a mãe desempenha papel primário nos cuidados com a criança, enquanto que o pai desempenha papel secundário. Em geral, o ato da maternidade envolve as atividades de aprender a cuidar do infante com competência, prover afeto, oferecer oportunidades para seu desenvolvimento, conciliar conflitos entre os membros da família e, da mesma forma, solucionar problemas práticos da vida familiar (Zamberlan \& Biasoli-Alves, 1997). Ainda segundo Zamberlan e Biasoli-Alves (1997), o papel do pai, por outro lado, envolve prover o sustento da família nuclear e partilhar, juntamente com a mãe, outros tipos de tarefas e rotinas que se traduzem em disciplina, valores morais, educativos e de autoridade.

Atualmente, percebe-se que um número crescente de famílias tem adotado o estabelecimento de um sistema de divisão quase igualitária de deveres e compromissos entre marido e mulher (Zamberlan \& Biasoli-Alves, 1997). No entanto, a concepção tradicionalista dos papéis desempenhados pela mãe e pelo pai continua ainda muito presente e se reflete na participação diferenciada de cada um destes atores sociais no contexto familiar (Seidl-de-Moura \& Ribas, 1998).

Dentre as diversas variáveis que também podem afetar as relações no contexto familiar destacam-se, por exemplo, experiência de maternidade primípara, trabalho materno fora de casa (Miller \& Harwood, 2001; Suizzo, 2002), efeitos de cuidados múltiplos e níveis de organização familiar (Zamberlan \& Biasoli-Alves, 1997). A estas variáveis é adicionada uma variável cultural, denominada de metas de socialização, que versa sobre diferentes padrões interativos em diferentes culturas e variações educacionais, ambos relacionados à responsividade materna/paterna. A seguir procurar-se-á definir metas de socialização tendo em conta que esta é a principal variável investigada neste estudo.

\section{Metas de socialização}

Estudiosos do desenvolvimento humano têm demonstrado a importância de se investigar a interface entre sociedade, família e socialização, enquanto base para a construção de redes sociais, ou seja, de contextos culturalmente estruturados que os indivíduos criam para eles mesmos e que, consequentemente, transmitem para suas crianças (Leyendecker e cols., 2002; Miller \& Harwood, 2001). Estas redes sociais se colocam como intermédio da orientação cultural dos pais expressa em seus objetivos de socialização e práticas de cuidado (Harwood, Miller, \& Lucca Irizarry, 1995; Harwood, Schöelmerich, Ventura-Cook, Schulze, \& Wilson, 1996; Miller \& Harwood, 2001). Nesse sentido, as metas de socialização são definidas como um conjunto de valores e crenças culturalmente construídas que se materializam em objetivos a longo prazo que os pais traçam para seus filhos e que influenciam as práticas de cuidado destes para com suas crianças (Miller \& Harwood, 2001).

Ao investigar a relação entre os contextos de criação das crianças e as metas de socialização, diversos estudos têm observado que culturas ocidentais tendem a promover a autonomia precoce enquanto que culturas não ocidentais tendem a incentivar as interrelações sociais próximas entre cuidadores e criança (Keller, 1998; Harwood, 1992). Por outro lado, estudos realizados no Brasil, onde seriam esperados resultados que indicassem uma maior ênfase dos participantes em qualidades sociocêntricas; sugerem uma tendência das mães brasileiras a estimularem o individualismo (Ruela e cols., 2005; Zamberlan \& Biasoli-Alves, 1997). Sobre este aspecto, Biasoli-Alves (1997) argumentou que a necessidade de desenvolvimento da autonomia da criança, visando à formação de um adulto competitivo, independente e realizado profissionalmente, tem se configurado como uma estratégia dos pais diante das novas exigências de um mundo globalizado, que valoriza o potencial produtivo do indivíduo. Desse modo, parece compreensível que a valorização de um ideal de homem moderno independente e autoconfiante esteja presente não apenas em culturas norte-americanas, mas também esteja sendo introduzida em outros contextos culturais, a exemplo da América Latina (Dessen \& Torres, 2002; Lordelo, Fonseca, \& Araújo, 2000).

Por outro lado, os estudos de Keller e cols. (2006) e Keller (2007) têm sugerido três tipos de orientações gerais referentes a crenças parentais e valores entre mães e pais de diferentes culturas (Alemã, Euro-Americana, Grega, Indiana, Chinesa, Mexicana e Costa Riquenha). O primeiro tipo de crenças refere-se a uma orientação frente ao desenvolvimento 
de um eu autônomo (aproximando-se a características individualistas), enquanto o segundo tipo refere-se ao desenvolvimento de um eu interdependente (aproximando-se a características sociocêntricas). Finalmente, o terceiro tipo de crenças refere-se ao desenvolvimento de um eu autônomorelacional, que representaria uma mescla dos dois anteriores e foi descrito por Kagitcibasi (1996) como uma orientação, a longo prazo, envolvendo uma valorização da autonomia e da auto-realização e, ao mesmo tempo, dando ênfase a manutenção de relações íntimas entre a família e o grupo social. Este último tipo de orientação foi identificado em mães da Costa Rica e México sugerindo uma tendência homogênea para os países latinos quanto às metas de socialização do tipo autônomo-relacional (Keller e cols., 2006).

No entanto, diante da grande variabilidade cultural do Brasil, pode ser difícil chegar a uma caracterização geral ou homogênea das metas de socialização de mães e pais brasileiros (Seidl-de-Moura e cols., 2008). Segundo Dessen e Torres (2002), baseados no modelo de cinco subculturas desenvolvido pelo antropólogo brasileiro Darcy Ribeiro (para uma revisão desse modelo ver Ribeiro, 1997), grupos com tendências individualistas (regiões Sul e Sudeste do país), tendências sociocêntricas (região norte e nordeste do país) e tendências mistas (região centro-oeste do país) podem ser encontrados na sociedade brasileira, levando a acreditar em uma heterogeneidade nas metas de socialização entre mães brasileiras.

Dentro deste debate, estudo realizado por Seidl-deMoura e cols. (2008) com mães de sete cidades do Brasil, a saber, Belém, João Pessoa, Salvador, Campo Grande, Rio de Janeiro, Florianópolis e Porto Alegre, evidenciou que, de um modo geral, as mães brasileiras deram mais ênfase as categorias auto-aperfeiçoamento e bom-comportamento, apresentando uma tendência à reforçar o desenvolvimento de um eu ao mesmo tempo autônomo e relacional. No entanto, quando as cidades foram divididas em regiões e avaliadas separadamente foram percebidas três tendências principais. As mães do norte e nordeste do país (cidades de Belém, João Pessoa e Salvador) apresentaram um padrão similar valorizando igualmente as metas de auto-aperfeiçoamento e bom comportamento. Já as mães do sul do país (cidades de Florianópolis e Porto Alegre) apresentaram maiores médias na categoria bom comportamento do que na categoria autoaperfeiçoamento. Por fim, um terceiro padrão foi encontrado no grupo de mães da cidade do Rio de Janeiro. Estas deram mais importância ao auto-aperfeiçoamento que ao bom comportamento da criança. Além disso, na ocasião foram observados efeitos das variáveis tamanho da cidade e nível educacional das mães nas metas de socialização (para uma revisão ver Seidl-de-Moura e cols., 2008).

Tendo em vista os estudos que investigaram as metas de socialização em diferentes culturas, parece ser igualmente interessante estudar como estas se expressam em mães e pais considerando que a literatura aponta que cada um destes atores sociais desempenha papéis diferenciados na criação dos filhos (Bridges e cols., 1988; Dessen, 1997; Ely \& Gleason, 1997; Zamberlan \& Biasoli-Alves, 1997). No entanto, estudo recente realizado por Prado, Vieira e Piavanotti (2005) em Santa Catarina tem apontado muito mais concordâncias que divergências entre mães e pais em relação às expectativas sobre as qualidades futuras dos filhos na faixa etária de três a seis anos. Neste estudo os casais apresentaram expectativas semelhantes em relação ao desenvolvimento do potencial econômico e pessoal dos filhos, e quanto ao cumprimento de expectativas valorizadas socialmente, como, por exemplo, ser honesto, trabalhador e seguidor de leis. Neste caso, os maiores níveis de resposta corresponderam às categorias $a u$ to-aperfeiçoamento e expectativa social, respectivamente.

Além de ser importante considerar que tipo de influência os papéis exercidos pela mãe e pelo pai desempenham nas metas de socialização que são traçadas para os filhos, parece também pertinente considerar o sexo da criança uma vez que diferentes expectativas que incutem valores socialmente construídos podem também ser percebidas nos comportamentos, habilidades e atitudes que uma cultura considera apropriada para o sexo masculino e feminino. Por exemplo, geralmente espera-se que as mulheres sejam condescendentes e carinhosas enquanto que os homens sejam ativos e competitivos (Costa \& Antoniazzi, 1999), o que sugere que metas relacionadas à emotividade e ao bom comportamento sejam preferidas para as meninas, enquanto que para os meninos a preferência seria por metas relacionadas ao auto-aperfeiçoamento.

No entanto, poucos estudos têm sido empreendidos no que tange especificamente a temática metas de socialização e diferenças de gênero. Na literatura foram identificados apenas dois estudos que tenham testado diferenças de gênero quanto às metas de socialização. Um destes estudos foi realizado por Citlak, Leyendecker, Scholmerich, Driessen e Harwood (2008) com mães turcas e alemãs, no qual não foi identificada diferenças quanto às metas de socialização para meninos e meninas. O segundo estudo foi empreendido por Leyendecker e cols. (2002) e mostrou que mães da América Central dão mais importância a metas relacionadas ao autocontrole para meninos que para meninas.

Diante desta problemática, o presente estudo objetivou investigar as metas de socialização de mães e pais acerca do futuro dos seus filhos. Adicionalmente, pretendeu-se verificar a influência do gênero da criança nas metas traçadas pelas mães e pais e averiguar a concepção que esses têm acerca do papel que devem desempenhar para que as metas se realizem.

\section{Método}

\section{Participantes}

Participaram do estudo 26 casais da cidade de João Pessoa, que eram pais pela primeira vez de filhos com idade entre dois e 40 meses, sendo 17 meninos e nove meninas. A idade dos participantes variou entre 17 e 37 anos, sendo 
a idade média das mães 24 anos $(d p=2,26)$ e dos pais 26 anos $(d p=2,30)$. O nível de escolaridade dos casais variou em sete categorias (de ensino fundamental incompleto à pósgraduação), sendo o ensino médio completo o de maior frequência (seis mães e nove pais) e estes foram classificados em três classes socioeconômicas: média-alta $(\mathrm{n}=7)$, médiabaixa $(n=10)$ e baixa $(n=9)$. Os principais critérios para a seleção da amostra foram que os casais experienciassem a maternidade e paternidade pela primeira vez, residissem com a criança com idade inferior que 48 meses e voluntariamente aceitassem fazer parte do estudo.

\section{Instrumentos}

Para coletar os dados sociodemográficos foi utilizada uma ficha de informações sobre a família composta de questões fechadas com opções pré-estabelecidas, o que permitiu $\mathrm{o}$ acesso a dados referentes à idade, nível educacional, estado civil e profissão da mãe e do pai, idade e sexo dos filhos. Além disso, os participantes responderam a uma entrevista semi-estruturada desenvolvida por Harwood e cols. (1996) e adaptada para o contexto brasileiro por Seidl-de-Moura e cols. (2008), composta por duas questões abertas que buscaram investigar as expectativas dos pais com relação ao futuro dos seus filhos. As questões referiam-se às qualidades que os pais desejariam que seu filho(a) tivesse como adulto e o que eles acham necessário fazer, como pais, para que a criança pudesse desenvolver essas qualidades. Duas outras perguntas foram incluídas como complementares visando a questionar alguma outra qualidade que os pais desejariam para o filho(a) e o que mais estes acham necessário, respectivamente.

\section{Procedimentos de coleta de dados}

O estudo foi aprovado pelo Comitê de Ética do Centro de Ciências da Saúde - CCS da Universidade Federal da Paraíba - UFPB, por cumprir os requisitos exigidos na pesquisa com seres humanos e, em seguida, o procedimento de coleta de dados foi iniciado. Deste modo, os participantes foram contatados através de indicações de parentes e pessoas conhecidas dos pesquisadores e mediante indicações dos entrevistados. No primeiro contato, procurou-se explicar os objetivos da pesquisa através de uma carta de apresentação. Em seguida foi apresentado o Termo de Consentimento Livre e Esclarecido. No caso de concordância e disponibilidade os participantes assinavam o referido termo e era estabelecido um horário conveniente para a realização das entrevistas domiciliares. Estas foram gravadas e ocorreram em momentos distintos com os pais e mães.

\section{Procedimentos de análise dos dados}

As entrevistas foram transcritas integralmente e analisadas segundo a análise de conteúdo quantitativa proposta por Bardin (1977) e tomando como referência as categorias estabelecidas por Harwood e cols. (1996) e adaptadas por Seidl-de-Moura e cols. (2008). Duas pesquisadoras formadas em Psicologia e experientes na temática das metas de socialização participaram desta etapa. Neste sentido, as respostas para a primeira questão, Que qualidades você desejaria que seu filho(a) tivesse como adulto?, foram classificadas segundo as seguintes categorias: auto-aperfeiçoamento, autocontrole, emotividade, expectativas sociais e bom comportamento. A categoria auto-aperfeiçoamento diz respeito a preocupação com que a criança se torne autoconfiante e independente e que desenvolva totalmente seus talentos e capacidades como indivíduo. Já o autocontrole relaciona-se a preocupação com que a criança desenvolva a capacidade de controlar impulsos negativos de ganância, agressão ou egocentrismo. A emotividade refere-se a preocupação com que a criança desenvolva a capacidade para intimidade emocional com outras pessoas, e que seja amada, enquanto que a categoria expectativas sociais expressa a preocupação dos pais com que a criança atenda a expectativas sociais de ser trabalhador, honesto e seguidor de leis. Por fim, na categoria bom comportamento foram classificadas as falas que expressavam a preocupação com que a criança se comportasse bem, tivesse bom relacionamento com os outros e desempenhasse bem os papéis esperados (bom pai, boa mãe, boa esposa), especialmente em relação à família. De acordo com Harwood e cols. (1996), as categorias auto-aperfeiçoamento e autocontrole são características de metas individualistas enquanto que as categorias emotividade, bom comportamento e expectativas socias refletem metas sociocêntricas.

Por sua vez, as respostas à segunda pergunta $O$ que você acha necessário para que seu filho possa desenvolver as qualidades apontadas por você? foram classificadas em termos das possíveis estratégias de ação adotadas pelos pais. Harwood e cols. (1996) e Seidl-de-Moura e cols. (2008) sugeriram as seguintes classificações para estas estratégias: centradas em si e centradas no contexto. As estratégias de ação centradas em si se referem aos pais serem modelos ou oferecerem modelos para os filhos, disciplinar, aconselhar e ensinar por demonstração ou participação. Já as estratégias centradas no contexto versam sobre oferecer boas oportunidades sociais e dar educação de qualidade.

Em seguida, foi realizado um teste de fidedignidade para estimar se as unidades de análise foram adequadamente inseridas em suas respectivas categorias. Para o teste de fidedignidade contou-se com a participação de três psicólogas que não estavam diretamente envolvidas no estudo e que atuaram como juízes. A concordância era verificada entre dois juízes e o terceiro chamado em caso de discordância. As categorias pré-estabelecidas foram adotadas apenas em caso de consenso entre os juízes. Em caso de discordância uma nova categoria era criada, tendo sido denominada de outros. Desse modo, foi calculado um índice de fidedignidade a partir da seguinte fórmula: $\sum \mathrm{A} / \sum(\mathrm{A}+\mathrm{D}) \mathrm{x} 100$, que se refere ao somatório dos acordos obtidos com a análise dos juízes dividido pelo somatório de acordos e desacordos da mesma análise de juízes multiplicado por cem. $\mathrm{O}$ índice de fidedignidade 
para o caso da categorização das entrevistas realizadas com as mães foi de $93,97 \%$ e para àquelas realizadas com os pais foi de $89,05 \%$. Já o índice de fidedignidade geral para a categorização como um todo foi de $91,74 \%$. Por fim, obtiveramse as frequências e porcentagens de cada categoria para mães e pais e para meninos e meninas e o teste Mann-Whitney foi administrado a fim de verificar a significância das diferenças obtidas. Para se estimar o nível de significância adotou-se $p>0,05$.

\section{Resultados}

Para a pergunta 1 (Que qualidades você desejaria que seu filho(a) tivesse como adulto?) e 1 b (Que outra qualidade você desejaria?), as entrevistas realizadas com as mães apresentaram um total de 166 unidades de análise enquanto que aquelas realizadas com os pais apresentaram um total de 137 unidades de análise. A análise específica para as respostas a estas perguntas são apresentadas na Figura 1.

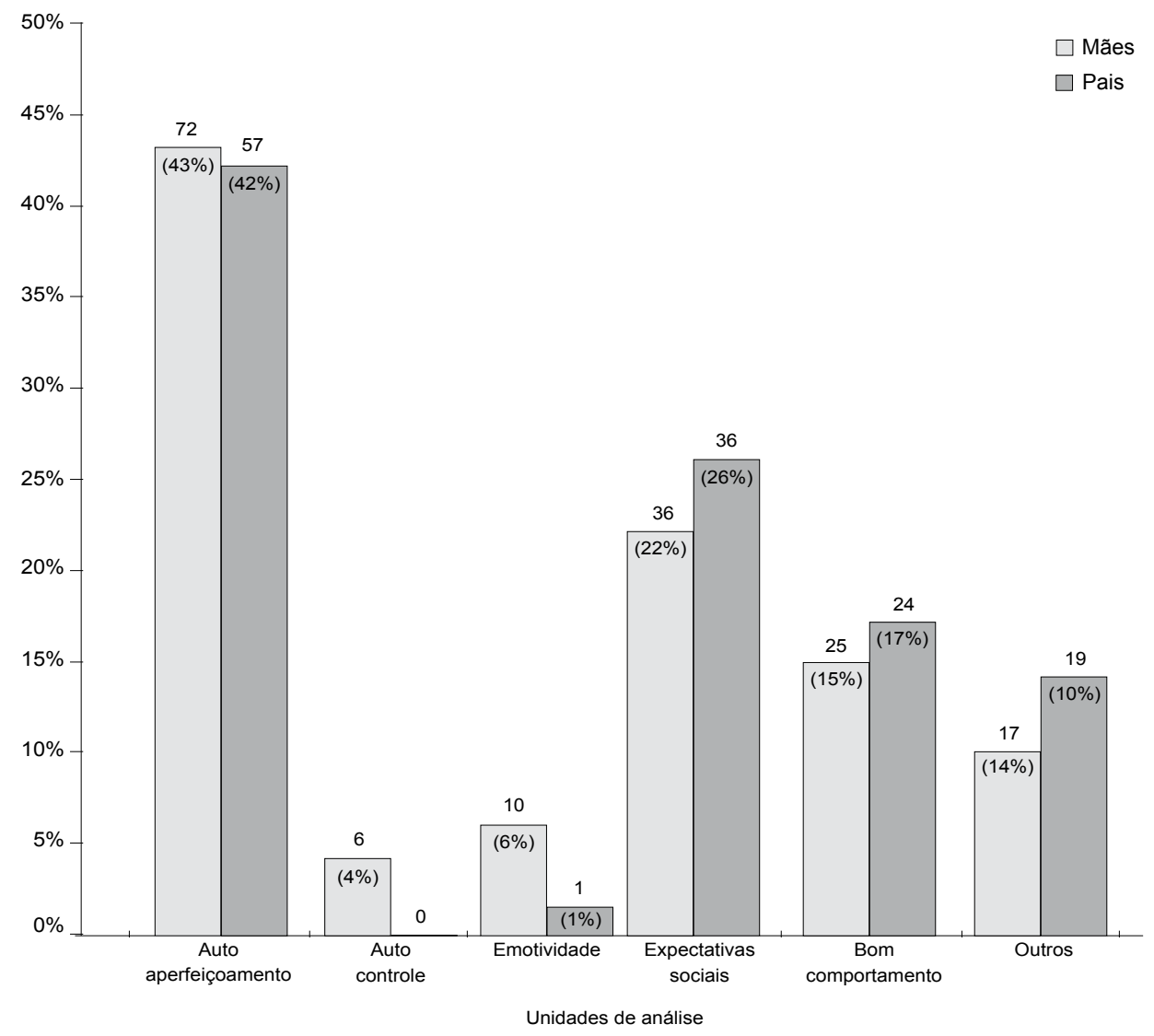

Figura 1. Total de unidades de análise e porcentagens classificadas para mães e pais nas metas de socialização

A categoria auto-aperfeiçoamento foi a categoria mais cotada tanto pelas mães quanto pelos pais. Exemplos de respostas classificadas nesta categoria relacionaram-se a preocupação com que o filho fosse autoconfiante, tivesse um bom desempenho profissional, conseguisse alcançar seus objetivos, fosse independente, conseguisse desligar-se do vínculo com a mãe ou que a criança aprendesse, quando adulto, a cuidar dele mesmo. Uma das falas das mães que expressou essa categoria foi: que meu filho consiga ser independente de mim, correndo atrás de seus objetivos e realizando-se profissionalmente (M4). No caso dos pais uma fala representativa desta categoria foi: que ele tenha desenvoltura para se sobressair e se tornar um grande profissional (P1).

Em segundo lugar, pais e mães apresentaram preocupação em que a criança atendesse as expectativas sociais de ser um adulto honesto, trabalhador e seguidor das leis sociais como pode ser visto nas verbalizações a seguir. Que ele seja um adulto honesto, tenha discernimento para saber o que está certo e o que está errado, seja uma pessoa de bons princípios e trabalhadora (M1); Que ele seja uma pessoa digna, honesta, descente e cumpra seus deveres perante a sociedade (P6).

Em sequência vem a categoria bom comportamento na qual as mães e pais apresentaram preocupação com que a criança se comportasse bem, se relacionasse bem com os outros e desempenhasse papéis esperados. Que ela seja uma pessoa sociável, educada, tenha um bom vínculo com as pessoas com as quais ela têm parentesco, sua familia e seus amigos; que ela se comporte bem e siga sempre os conselhos dos mais velhos (M11); Que ele valorize a relação com o 
próximo, seja educado e comportado, seja um bom pai, um bom marido e um bom filho (P8).

A categoria outros aparece como a quarta categoria mais cotada por mães e por pais. Nesta categoria incluiramse respostas que versaram sobre que o filho fosse um adulto saudável e/ou que possuísse princípios religiosos, como, por exemplo, as seguintes falas: Que seja uma pessoa sadia e que tenha fé, bastante fé em Deus (M8); Que ela tenha saúde e que seja uma pessoa religiosa (P16).

Por sua vez, na categoria emotividade, relacionadas ao fato de que a criança fosse afetiva com as pessoas, fosse amada e amasse reciprocamente, foi constatada apenas uma pequena menção por parte das mães e por apenas um dos pais: Que ele seja afetivo e amoroso com as pessoas ao lado dele e que seja feliz (M13); Que ele seja muito amado por todos (P13).

Por fim, na categoria autocontrole, as mães demonstraram preocupação com que os filhos fossem capazes de controlar impulsos negativos, como, por exemplo, de agressividade. Que ele não fosse uma pessoa que gostasse de brigar, que fosse uma pessoa tranquila, paciente e não tivesse preconceitos (M7). No entanto, os pais não fizeram qualquer menção durante as entrevistas a respostas que se enquadrassem nesta categoria.

Em geral, não se verificou grande variabilidade na quantidade de unidades de análise e, consequentemente, nas porcentagens de respostas entre as mães e os pais no que se refere à pergunta $1 \mathrm{a}$ e $1 \mathrm{~b}$. $\mathrm{O}$ teste Mann-Whitney foi aplicado a fim de identificar alguma diferença entre mães e pais no que diz respeito às metas de socialização. Os resultados indicaram que as diferenças não foram significativas $(p>0,05)$, o que reforçou a proposição de que mães e pais não se diferenciam quanto às metas de socialização preferidas por estes. No entanto, quando se comparou as respostas das mães e pais no que diz respeito ao gênero das crianças, foram encontrados os seguintes resultados expressos na Tabela 1.

Tabela 1

Total de unidades de análise e porcentagens classificadas para mães e pais nas metas de socialização em função do sexo da criança

\begin{tabular}{lcccc}
\hline & \multicolumn{2}{c}{ Meninos (N=17) } & \multicolumn{2}{c}{ Meninas (N=9) } \\
\cline { 2 - 5 } & Mães & Pais & Mães & Pais \\
\hline $\begin{array}{l}\text { Auto- } \\
\text { aperfeiçoamento }\end{array}$ & $41(39 \%)$ & $34(36 \%)$ & $31(51 \%)$ & $23(55 \%)$ \\
$\begin{array}{l}\text { Autocontrole } \\
\text { Emotividade }\end{array}$ & $5(5 \%)$ & $0(0 \%)$ & $1(2 \%)$ & $0(0 \%)$ \\
$\begin{array}{l}\text { Expectativas } \\
\text { sociais }\end{array}$ & $27(26 \%)$ & $30(31 \%)$ & $9(15 \%)$ & $6(14 \%)$ \\
$\begin{array}{l}\text { Bom } \\
\text { comportamento }\end{array}$ & $19(18 \%)$ & $18(19 \%)$ & $6(10 \%)$ & $6(14 \%)$ \\
$\begin{array}{l}\text { Outros } \\
\text { Total }\end{array}$ & $10(9 \%)$ & $12(13 \%)$ & $7(11 \%)$ & $7(17 \%)$ \\
\hline
\end{tabular}

Pode-se perceber, de acordo com a Tabela 1, um maior número de unidades de análise e, consequentemente, uma maior porcentagem destas na categoria auto-aperfeiçoamento, para ambos, pais e mães, independentemente do sexo da criança. Especificamente quando a criança era do sexo masculino as mães, mais que os pais, apresentaram maior preocupação com o auto-aperfeiçoamento do filho. Ainda quando se tratava da criança do sexo masculino destacou-se também a categoria expectativas sociais. Nesse caso, os pais apresentaram mais expectativas sociais sobre o filho que o fizeram as mães. Já quando a criança era do sexo feminino, a categoria auto-aperfeiçoamento apresentou maioria absoluta de unidades de análise destacando-se das demais. Neste caso, os pais apresentaram uma porcentagem um pouco superior a das mães.

Buscou-se ainda testar se pais e mães apresentariam diferenças significativas quanto às metas de socialização quando a criança era do sexo masculino ou feminino. Assim, o teste Mann-Whitney foi administrado para a amostra específica de mães e de pais. No caso das mães, não foi observada diferença significativa em nenhuma das categorias em relação ao sexo da criança $(p>0,05)$, o que sugere que as mães não se diferenciam em relação às metas de socialização fossem seus filhos meninos ou meninas. Já no caso dos pais observou-se uma diferença significativa apenas quanto a categoria expectativas sociais (estatística $\mathrm{U}=$ 10,$000 ; p<0,05$ ), de modo que estes apresentaram maiores expectativas sociais quando o filho era do sexo masculino $(M=10,67)$ que quando era do sexo feminino $(M=5,00)$.

No que se refere à pergunta $2 \mathrm{a}(O$ que você acha necessário para que seu filho possa desenvolver as qualidades apontadas por você?) e $2 \mathrm{~b}$ ( $O$ que mais você acha necessário?), as entrevistas realizadas com as mães apresentaram um total de 76 unidades de análise enquanto que aquelas realizadas com os pais apresentaram um total de 50 unidades de análise. Os resultados da análise específica para as respostas a estas perguntas são apresentados na Figura 2.

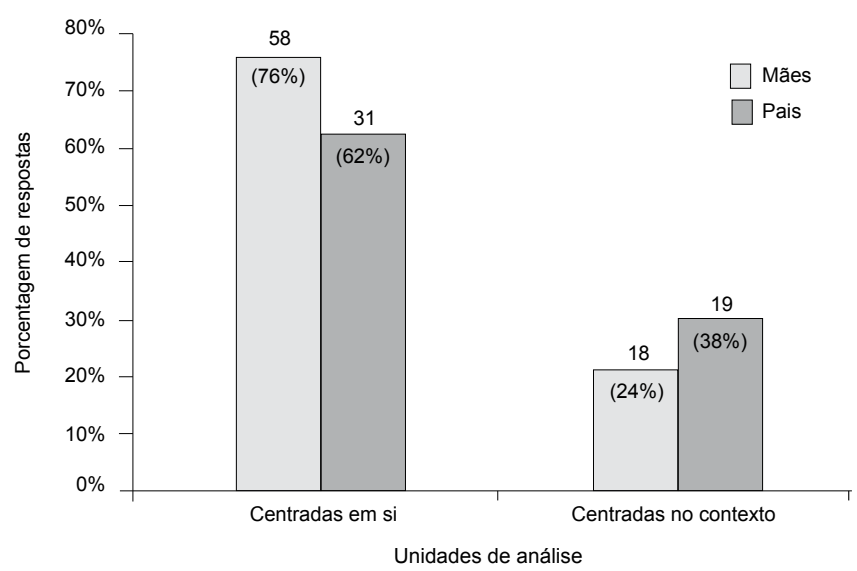

Figura 2. Estratégias de ação dos pais e das mães 
Percebe-se a partir do gráfico que as mães e pais apresentaram uma maior freqüência de categorizações quanto às estratégias de ação centradas em si. Neste caso, as mães apresentaram uma porcentagem de unidades de análise superior aos pais. A subunidade de análise mais freqüente para as estratégias de ação centradas em si, no caso das mães, foi: (a) dar amor, carinho, compreensão e apoio à criança (27 unidades; 47\%); (b) impor limites (15 unidades; 25\%); (c) passar seus valores para a criança (oito unidades; $14 \%$ ) utilizando estratégias de conversar, aconselhar, ensinar por demonstração ou participação em brincadeiras e oferecer modelos para a educação da criança; e, (d) proporcionar um ambiente familiar saudável, sem brigas e discussões entre os pais, com uma família unida e sem maus tratos (oito unidades; $14 \%$ ). Por sua vez, nesta categoria, os pais apontaram: (a) passar seus valores para os filhos (13 unidades; 42\%); (b) dar apoio e acompanhar a criança a cada dia (nove unidades; 29\%); (c) corrigir e repreender (cinco unidades; 17\%); e, (d) passar responsabilidade e confiança para o filho através de conversas (quatro unidades; 12\%). Diferentemente do que foram observados nas entrevistas com as mães, os pais não se referiram a adotar estratégias de ação centradas em si de âmbito afetivo, como, por exemplo, dar amor e carinho.

No que se refere à categoria centrada no contexto, os pais apresentaram uma porcentagem de classificações de unidades de análise um pouco maior que as mães. Uma análise mais detalhada sobre a frequência das subunidades revelou que das estratégias de ação centradas no contexto as mães referiram-se à escola como contexto principal para oferecer uma educação de qualidade (10 unidades; 56\%), seguida da influência dos pares (oito unidades; 44\%). Os pais também apontaram a escola como principal contexto de interação e educação (11 unidades; 60\%) e, além disso, se referiram ao governo e à sociedade como importantes mecanismos para promoção de um desenvolvimento saudável para seus filhos (oito unidades; $40 \%$ ).

Os resultados do teste Mann-Whitney indicaram uma diferença significativa entre mães e pais quanto à estratégia de ação centrada de si (estatística $\mathrm{U}=135,5 ; p<0,05$ ). Neste caso, mães $(M=24,11)$ pareceram adotar mais este tipo de estratégia do que os pais $(\mathrm{M}=17,03)$. No caso das estratégias de ação centradas no contexto não foi identificada diferença significativa entre mães e pais $(p>0,05)$.

\section{Discussão}

Mães e pais do presente estudo apresentaram uma maior frequência de unidades de análise na categoria $a u$ to-aperfeiçoamento. Isto pode estar relacionado com uma questão cultural que aponta para uma tendência, mesmo em países latinos, a enfatizar princípios de uma sociedade individualista que valoriza a autonomia, a independência e o sucesso profissional (Biasoli-Alves, 1997; Ruela e cols., 2005; Zamberlan \& Biasoli-Alves, 1997). No entanto, também foi percebida uma grande ênfase tanto por mães e pais na categoria expectativas sociais, teoricamente relacionada a uma cultura com orientação sociocêntrica que enfatiza o desenvolvimento de qualidades desejáveis socialmente e que da prioridade ao aspecto relacional entre criança, família e sociedade (Harwood e cols., 1996). Neste sentido, pode-se pensar que os participantes do presente estudo apresentaram um perfil que se aproxima a um padrão autônomo-relacional das metas de socialização esperados para países da América Latina (Keller, 2007; Keller e cols., 2006) uma vez que estes desejaram que seus filhos fossem autoconfiantes, independentes e bem sucedidos profissionalmente, ao mesmo tempo que valorizaram que eles fossem honestos e cumpridores de suas obrigações com a família e com a sociedade. Além disso, a ênfase na categoria expectativas sociais, identificada no presente estudo, não seguiu o padrão esperado para a região Norte e Nordeste do Brasil, representada, no estudo de Seidl-de-Moura e cols. (2008), pelas cidades de João Pessoa, Belém e Salvador, no qual a categoria bom comportamento foi a categoria de orientação sociocêntrica mais evidenciada pelas mães desta região. Este achado pode sugerir então a existência não só de uma diferença regional, mas também de uma especificidade em termos da cidade de origem dos participantes. Apesar de estar situada na região Norte-Nordeste, João Pessoa é uma cidade menor em dimensão geográfica e menos populosa que Belém e Salvador, logo se pode pensar em diferentes padrões intraculturais entre estas cidades que estariam influenciando as crenças parentais.

Cabe ainda destacar que não foi identificada diferença estatisticamente significativa entre as mães e os pais nas metas de socialização, o que supõe mais semelhanças do que diferenças entre os participantes. Este dado corrobora os achados do estudo conduzido por Ruela e cols. (2005) no qual foi identificado que mães e pais apresentaram níveis semelhantes de resposta nas categorias auto-aperfeiçoamento e expectativa social. Argumenta-se que pelo fato de mães e pais compartilharem o mesmo nicho de desenvolvimento seria natural que apresentassem padrões de crenças similares (Prado e cols., 2005; Zamberlan \& Biasoli-Alves, 1997).

Quando se comparou as respostas de mães e pais em função do sexo da criança verificaram-se baixos índices em categorias como autocontrole e emotividade e altos índices principalmente nas categorias auto-aperfeiçoamento e expectativas sociais. Neste sentido, independente do sexo da criança, tanto as mães quanto os pais primaram pelos ideais de uma sociedade individualista de pleno desenvolvimento das capacidades do indivíduo e sucesso profissional e, ao mesmo tempo, enfatizaram características sociocêntricas que revelam uma preocupação em manter princípios morais $\mathrm{e} o$ respeito às normas.

Apesar do baixo índice, percebeu-se uma maior referência por parte das mães em relação às filhas quanto a qualidades relativas à emotividade, o que não ocorreu quando entre aquelas que tinham filhos do sexo masculino. Isto pode estar relacionado às expectativas de que as mulheres sejam mais carinhosas e condescendentes enquanto que os homens sejam ativos e competitivos, conforme apontado por Costa e Antoniazzi (1999). 
Outro aspecto interessante ainda no que diz respeito à comparação entre as metas de mães e pais em função do sexo da criança refere-se a categoria bom comportamento. Geralmente mais esperado para as meninas do que para os meninos (Costa \& Antoniazzi, 1999; Seidl-de-Moura \& Ribas, 1998; Zamberlan \& Biasoli-Alves, 1997), qualidades referentes a esta categoria foram mencionadas tanto por pais como pelas mães, independentemente do sexo da criança. Ambos pareciam almejar que seus filhos se tornassem adultos que se comportassem apropriadamente, que se relacionassem bem em grupo e desempenhassem bem os papéis esperados.

Apesar das frequências e porcentagens sugerirem diferentes metas de socialização para meninos e meninas, vale salientar que foi identificada diferença estatisticamente significativa apenas no que diz respeito aos pais em relação à categoria expectativas sociais, de modo que estes apresentaram mais expectativas de um adulto honesto e seguidor das normas sociais quando o filho era do sexo masculino do que quando era do sexo feminino. Neste sentido, embora seja consenso na literatura que características infantis, como, por exemplo, o gênero, podem provocar estilos interativos peculiares e, consequentemente, expectativas diferenciadas para meninos e meninas (Braz \& Salomão, 2002; Oliveira, Frizzo, \& Marin, 2000; Silva, 2004), esta diferenciação pode ser influenciada pelo tipo de relação que as crianças estabelecem com seus pais e pelas qualidades valorizadas por estes e que refletem características de um adulto pautadas no que é valorizado pela cultura (Gouveia \& Clemente, 2000; Harwood, 1992; Leyendecker e cols., 2002; Miller \& Harwood, 2001). Neste sentido, as possíveis diferenças sugeridas no presente estudo, no que se refere às metas de socialização em função do sexo da criança, poderiam estar sendo influenciadas pela cultura brasileira que apesar de apresentar uma tendência aos valores individualistas oriundos da influência norte-americana ainda revela algumas crenças e valores latinos arraigados.

Por fim, quanto às estratégias de ação adotadas, mães e pais apresentam frequência maior nas estratégias de ação centradas em $s i$, além de apresentarem frequências similares também nas estratégias centradas no contexto. No entanto, houve diferença estatisticamente significativa entre os participantes nas estratégias centradas em si. Neste caso, as mães pareceram adotar mais este tipo de estratégia que os pais. Além disso, na análise mais detalhada observou-se que os tipos de estratégias centradas em si também se diferenciaram. Mães revelaram utilizar mais estratégias centradas em si relacionadas a dar amor e carinho, enquanto que os pais se referiram mais a transmitir valores aos filhos. Nesse sentido, pode-se pensar que as mães do presente estudo ainda possuem crenças relacionadas ao papel de mãe, tradicionalmente esperado, de prover afeto e cuidados primários a criança (Zamberlam e cols., 1997). No entanto, a ênfase em tais estratégias pode depender da faixa etária em que a criança se encontra. No presente estudo a idade das crianças variou de dois a 40 meses o que representa um período específico do desenvolvimento, no qual os conflitos do dia a dia giram em torno de atender as necessidades básicas do bebê. Assim, à medida que a criança cresce suas necessidades desenvolvimentais se modificam e tendem a modificar-se também as crenças dos pais a respeito de suas próprias estratégias e metas (para uma revisão ver Freitas, Shelton, \& Tudge, 2008; Tudge e cols., 2006). Logo, as estratégias de ação centradas em si se tornam menos frequentes à medida que a criança amplia suas relações sociais e inicia a fase escolar (Ely \& Gleason, 1997).

\section{Considerações finais}

No presente estudo, verificou-se que, de forma geral, os pais e mães apresentam um padrão similar de metas de realização, enfatizando, principalmente, as categorias autoaperfeiçoamento e expectativas sociais, o que reforça a concepção de um sistema de orientação autônomo-relacional para as metas de socialização. No que concerne às comparações realizadas em função do gênero da criança, conclui-se que os genitores diferiram em termos das expectativas sociais, já que os pais apresentaram uma maior ênfase nessa categoria quando a criança era do sexo masculino. Além disso, no que se refere às estratégias de ação, particularmente as estratégias centradas em si são mais relatadas por mães o que sugere um papel parental de cuidar do infante e prover amor e carinho, no entanto, tal estratégia pode ser típica da faixa etária em que as crianças se encontram.

Diante destes achados cabe apontar as limitações do presente estudo e apresentar sugestões para estudos futuros. Primeiramente, embora a utilização das categorias pré-estabelecidas tenha facilitado a concordância entre os juízes, levando a crer que estas podem ser indicadores consistentes do sistema de crenças culturais das mães e pais, tais categorias não conseguiram abarcar 10 a 14 por cento das falas dos participantes que foram, então, classificadas na categoria outros. Assim, poder-se-ia pensar em acrescentar uma nova categoria, ou até mesmo duas, que versassem sobre características relacionadas a ser um adulto religioso e/ou que dessem ênfase a saúde física. Estes aspectos podem ser uma peculiaridade da amostra pessoense ou, talvez, das mães e dos pais brasileiros.

Além disso, no presente estudo não foi explorada a influência de variáveis socioeconômicas nas metas de socialização como, por exemplo, o nível de escolaridade dos participantes e o tamanho das cidades. Não existem dúvidas de que tais variáveis influenciam o sistema de crenças parentais e tal relação já tem sido conhecida pela literatura (Harwood e cols., 1995; Harwood e cols., 1996; Miller \& Harwood, 2001; Peregrino, 2006). No entanto, fazer comparações em função dos dados demográficos não constituiu um objetivo do presente estudo que contou apenas com uma amostra de mães e pais residentes na capital do estado paraibano. Estudos futuros poderiam ser conduzidos considerando tais variáveis socioeconômicas, a exemplo daquele 
conduzido por Seidl-de-Moura e cols. (2008) e comparando, por exemplo, grupos de áreas urbanas e rurais de diferentes regiões do Brasil.

Sugere-se, ainda, que estudos futuros comparem o nível de concordância entre as metas de socialização de cada casal. Além disso, seria interessante investigar as crenças de outros membros da família, tendo em vista que no contexto familiar atual os pais se ausentam para trabalhar e as crianças ficam sob cuidados de avós, irmãos mais velhos e/ou babás.

Conclui-se que, considerando o escopo do estudo e suas limitações, a presente investigação permitiu compreender melhor como as metas de socialização e as estratégias de ação se configuram entre pais e mães, bem como as similaridades e diferenças no que diz respeito ao gênero da criança. Compreende-se, ainda, que este estudo contribuiu para o entendimento de alguns aspectos da complexidade cultural dos nichos de desenvolvimento brasileiros.

\section{Referências}

Bardin, L. (1977). Análise de conteúdo. Lisboa: Edições 70.

Biasoli-Alves, Z. M. M. (1997). Famílias brasileiras do século XX: Os valores e as práticas de educação da criança. Temas em Psicologia, 3, 36-49.

Braz, F. S., \& Salomão, N. M. R. (2002). A fala dirigida a meninos e meninas: Um estudo sobre input materno e sua variações. Psicologia Reflexão e Crítica, 15, 333-344.

Bridges, L. J., Connell, J. P., \& Belsky, J. (1988). Similarities and diferences in infant-mother and infant-father interaction in the strange situation: A component process analysis. Development Psychology, 24, 92-100.

Citlak, B., Leyendecker, B., Scholmerich, A., Driessen, R., \& Harwood, R. L. (2008). Socialization goals among first-and second-generation migrant Turkish and German mothers. International Journal of Behavioral Development, 32, 56-65.

Costa, F. O., \& Antoniazzi, A. S. (1999). A influência da socialização primária na construção da identidade de gênero: Percepções dos pais. Paidéia(Ribeirão Preto), 9, 67-74.

Dessen, M. A. (1997). Desenvolvimento familiar: Transição de um sistema triádico para poliádico. Temas em Psicologia, 3, 51-61.

Dessen, M. A., \& Torres, C. V. (2002). Family and socialization factors in Brazil: An overview. In W. J. Lonner, D. L. Dinnel, S. A. Hayes, \& D. N. Sattler (Eds.), Online readings in psychology and culture. Recuperado em 20 Junho 2008, de http://www.ed/ culture

Ely, R., \& Gleason, B. (1997). A socialização em diferentes contextos. In P. Fletcher \& B. Macwhinney (Orgs.), Compêndio da linguagem da criança (pp. 209-224). Porto alegre: Artes Médicas.

Field, T. (1978). Interaction patterns of primary versus secondary caretaker fathers. Development Psychology, 14, 183-184.
Freitas, L. B. L., Shelton, T. L., \& Tudge, J. R. H. (2008). Conceptions of US and Brazilian early childhood care and education: A historical and comparative analysis. International Journal of Behavioral Development, 32, 161-170.

Gouveia, V. V., \& Clemente, M. (2000). O individualismocoletivismo no Brasil e na Espanha: Correlatos sóciodemográficos. Estudos de Psicologia, 5, 317-346.

Harwood, R. L. (1992). The influence of culturally derived values on anglo and puerto rican mothers' perceptions of attachment behavior. Child Development, 63, 822-839.

Harwood, R. L., Miller, J. G., \& Lucca Irizarry, N. (1995). Culture and attachment: Perceptions of the child in context. New York: Guilford Press.

Harwood, R. L., Schöelmerich, A., Ventura-Cook, E., Schulze, P. A., \& Wilson, S. P. (1996). Culture and class influences on anglo and puerto rican mothers' beliefs regarding long-term socialization goals and child behavior. Child Development, 67, 2446-2461.

Kagitcibasi, C. (1996). The autonomous-relational self: A new synthesis. European Psychologist, 1, 180-186.

Keller, H. (1998). Diferentes caminhos de socialização até a infância. Revista Brasileira Crescimento $e$ Desenvolvimento Humano, 8, 1-14.

Keller, H. (2007). Cultures of infancy. Mahwah, NJ: Erlbaum.

Keller, H., Lamm, B., Abels, M., Relindis, Y., Borke,J., Henning, J., Papaligoura, Z., Holub, C., Lo, W., Tomiyana, A. J., Su, Y., Wang, Y., \& Chaudhary, N. (2006). Cultural models, socialization goals and parenting ethnotheories: A multicultural analysis. Journal of Cross-cultural Psychology, 37, 155-172.

Leyendecker, B., Lamb, M. E., Harwood, R. L., \& Schölmerich (2002). Mothers' socialization goals and evaluations of desirable and undesirable everyday situations in two diverse cultural groups. International Journal of Behavioral Development, 26, 248-258.

Lordelo, E. de R., Fonseca, A. L., \& Araujo, M. L. V. (2000). Responsividade do ambiente de desenvolvimento: Crenças e práticas como sistema cultural de criação de filhos. Psicologia: Reflexão e Crítica, 13, 73-80.

Miller, A. M., \& Harwood, R. L. (2001). Long-term socialization goals and the construction of infants' social neyworks among middle class anglo and puerto rican mothers. International Journal of Behavioral Development, 25, 450-457.

Oliveira, E. A., Frizzo, G. B., \& Marin, A. H. (2000). Atitudes maternas diferenciais para com meninos e meninas de quatro e cinco anos. Psicologia: Reflexão e Crítica, 13, 363-371.

Peregrino, R. R. (2006). Metas de socialização de mães de diferentes níveis sócio-econômicos. Dissertação de mestrado não-publicada, Universidade Federal da Paraíba, João Pessoa. 
Prado, A. B., Vieira, M. L., \& Piavanotti, M. R. A. (2005). Concepções de mães e pais sobre metas de socialização de filhos. In D. D. Dell'Aglio (Org.), Anais do Congresso Brasileiro de Psicologia do Desenvolvimento, Psicologia do desenvolvimento: Teorias, pesquisas e aplicações, 5 (p. 73). São Paulo: Casa do Psicólogo.

Ribeiro, D. (1997). O povo brasileiro: A formação e sentido do Brasil. São Paulo: Companhia das Letras.

Ruela, S. F., Seidl-de-Moura, M. L., Santana, L. S., Campos, K. N., Bandeira, T. T., \& Tesch, A. C. (2005). Uma análise de metas de socialização de mães de duas gerações em uma comunidade rural do estado do Rio de Janeiro. In D. D. Dell'Aglio (Org.), Anais do Congresso Brasileiro de Psicologia do Desenvolvimento, Psicologia do desenvolvimento: Teorias, pesquisas e aplicações, 5 (p. 74). São Paulo: Casa do Psicólogo.

Seidl-de-Moura, M. L., Lordelo, E., Vieira, M. L., Piccinini, C. A., Siqueira, J. O., Magalhães, C. M. C., Pontes, F. A. R., Salomão, N. M., \& Rimoli, A. (2008). Brazilian mothers' socialization goals: Intracultural differences in seven Brazilian cities. International Journal of Behavioral Development, 32, 465-472.

Seidl-de-Moura, M. L., \& Ribas, A. F. P. (1998). Interação precoce mãe-bebê e a concepção do desenvolvimento infantil inicial. Revista Brasileira de Crescimento e Desenvolvimento Humano, 8, 15-25.

Silva, A. M. P. M. (2004). Concepção materna sobre desenvolvimento de bebês de 0 a 12 meses e trocas interacionais mãe-bebê. Dissertação de mestrado nãopublicada, Universidade Federal da Paraíba, João Pessoa.

Suizzo, M. (2002). French parents' cultural models and child rearing beliefs. Internacional Journal of Behavioral Development, 26, 297-307.

Tudge, J. R. H., Odero, D., Piccinini, C. A., Doucet, F., Sperb, T. M., \& Lopes, R. S. (2006). A window into different cultural worlds: Young children's everyday activities in the United States, Brazil and Kenya. Child Development, 77, 1446-1469.

Zamberlan, M. T., \& Biasoli-Alves, Z. M. M. (1997). Interações familiares: Teoria, pesquisa e subsídios à intervenção. Londrina: Editora UEL.
Pollyane Kahelen da Costa Diniz é doutoranda em Psicologia Transcultural pelo Programa de Pós-graduação em Psicologia da Victoria University of Wellington, Nova Zelândia, bolsista Victoria PhD Scholarship.

Nádia Maria Ribeiro Salomão é Professora Adjunta do Departamento de Psicologia da Universidade Federal da Paraíba, Programa de Pós-graduação em Psicologia Social (Mestrado e Doutorado), campus I, coordenadora do Núcleo de Pesquisa em Interação Social e Desenvolvimento Infantil.

Recebido: 23/09/2008

$1{ }^{a}$ Revisão: 08/05/2009

$2^{a}$ Revisão: $21 / 10 / 2009$

Aceite final: 14/11/2009 